\title{
Giant Ureteral Stone in a Pediatric Patient: Case Report
}

\section{Yalcin Comert $\mathrm{HS}^{*}{ }^{1}$, Salci $\mathrm{G}^{1}$, Sarihan $\mathrm{H}^{1}$, Bozoglu $\mathrm{ST}^{1}$, Ozdogan EB $^{2}$ And Eyuboglu $\mathrm{I}^{3}$}

${ }^{1}$ Karadeniz Technical University, Faculty of Medicine, Department of Pediatric Surgery, Trabzon, Turkey

${ }^{2}$ Karadeniz Technical University, Faculty of Medicine, Department of Pediatric Nephrology, Trabzon, Turkey

${ }^{3}$ Karadeniz Technical University, Faculty of Medicine, Department of Radiology, Trabzon, Turkey

*Corresponding author: Yalcin Comert HS, MD, Assist. Prof, Karadeniz Technical University, Faculty of Medicine, Department of Pediatric Surgery, TR61080, Trabzon, Turkey, Fax: +90 462 3250518, Tel: +90 5327419246, E-mail: sonayyalcin@hotmail.com

Citation: Yalcin Comert HS, Salci G, Sarihan H, Bozoglu ST, Ozdogan EB, et al. (2021) Giant Ureteral Stone in a Pediatric Patient: Case Report. J Case Rep Stud 9(1): 103

Received Date: April 29, 2021 Accepted Date: June 21, 2021 Published Date: June 23, 2021

\begin{abstract}
A 9 year old boy refered to the hospital with abdominal pain insisting for 2 weeks. In his history there was any clinic symptom before. A giant opasification was detected in the distal part of the right ureter on plain abdominal film. Hematuria, hyperuricosuria, hyperoxaluria and hypocitraturia in his urinary analysis. Only a small right kidney (right kidney: 62x25mm; left kidney: 100x35mm) has found in the abdominal ultarsonography and an approximately a stone $42 \times 17 \mathrm{~mm}$ in seizes has detected in the magnetic resonance urography. In DMSA evaluation of the right kidney was $15,96 \%$ and the left kidney was $84,04 \%$. Ureterolitotomy was performed and the giant distal ureteral stone has removed.
\end{abstract}

Keywords: Giant Stone; Ureter; Pediatric 


\section{Introduction}

Primary ureteral stones are very rare in children. Ureteral stones which are bigger than $5 \mathrm{~cm}$ defined "giant ureteral stones" in adults in literatüre [1]. However in children there is any definition of the sizes of ureteral stone. Here we present a child with a distal ureteral stone which was bigger than $4 \mathrm{~cm}$ without any conspicuous clinic symptom history.

\section{Case}

A 9-year old boy presented with blunt abdominal pain insisting for two weeks. In his history there was any clinic symptom before. His systemic and urogenital examination was normal. Urinalysis showed hematuria (33), hyperuricosuria (18.5mg/kg), hyperoxaluria $\left(180 \mathrm{mg} / 1.73 \mathrm{~m}^{2}\right)$ and hypocitraturia $\left(313 \mathrm{mg} / 1.73 \mathrm{~m}^{2}\right)$. A giant opasification was detected in the distal part of the right ureter on plain abdominal film (Figure 1). Abdominal ultrasound revealed only a small right kidney (right kidney: 62x25mm; left kidney: 100x35mm). In magnetic resonance urography; the right kidney was $103 \times 62 \mathrm{~mm}$ in size and it was observed that the right calyceal structures and pelvis were dilated and blunting of the calyces. There was a right giant ureteral stone with dimensions of approximately $42 \times 17 \mathrm{~mm}$ with dilated proximal ureter and a dilatation up to $7 \mathrm{~mm}$ in the proximal of the stone in the right ureter (Figure 2). We did voiding cystourethrogram for exclude vesicoureteral reflux. Right kidney function was $15.96 \%$ and left kidney function was $84.04 \%$ in $99 \mathrm{~m}$ Tc-dimercaptosuccinic acid (DMSA). We did cystoscopy first and rule out any ureterocoele or ureteric abnormalities. A right ureterolitotomy operation was performed with a Mc Burney incision. During the surgery a giant distal ureteral stone with dimensions of $5 \times 2 \mathrm{~cm}$ was removed through a longitudinal incision (Figure 3 ). Therefore a double J stent was inserted into the ureter for both any underlying ureterovesical junction stenosis and for the ureters'healing. Lastly the incision was closed. The patient was discharged from the hospital on postoperative day 3 without any complication. Analysis of the stone showed it to be composed of "struvite $\left(\mathrm{NH}_{4} \mathrm{MgPO}_{4} \cdot 6 \mathrm{H}_{2} \mathrm{O}\right)$ ". The double J stent was removed under anesthesia 15 days postoperatively.

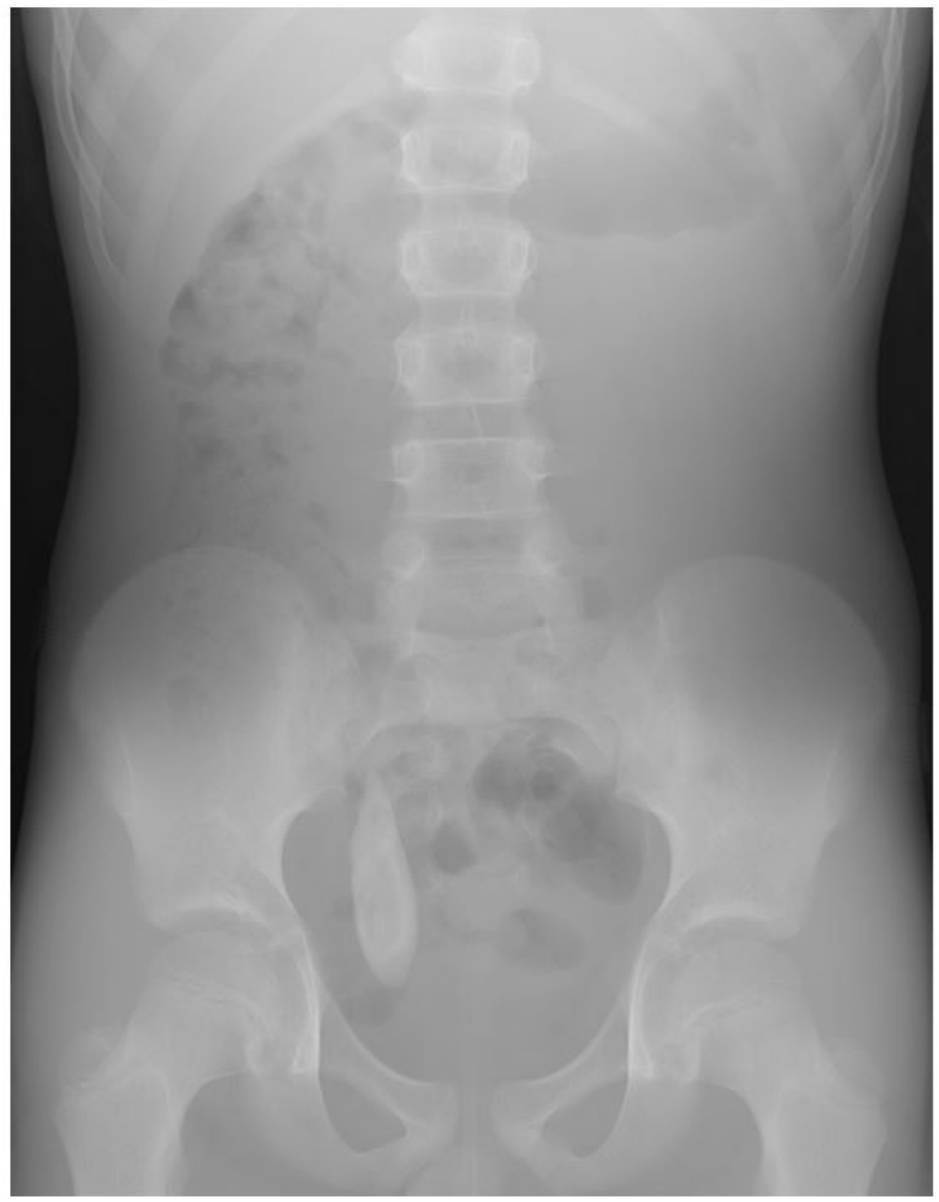

Figure 1: Plain abdominal film demonstrates a dense opacification in the line of right distal ureter 


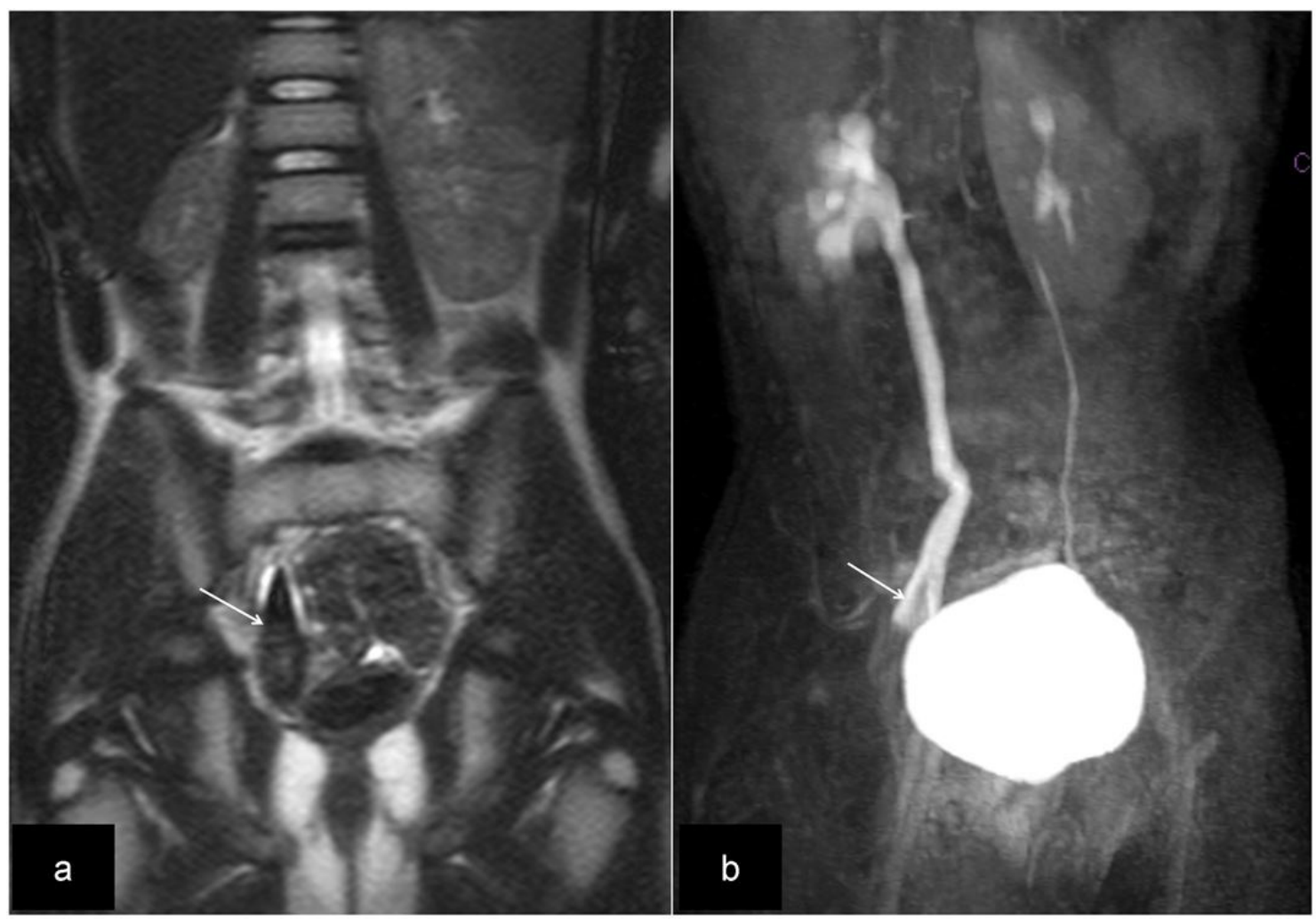

Figure 2: Coronal T2-HASTE MR image (a) reveals hypointense calculus in the right distal ureter and coronal multislice heavily T2-weighted (3D-T2-SPIR-TSE) MR image (b), shows filling defect in distal urter indicating calculus. The pelvicalyceal system and ureter are dilated

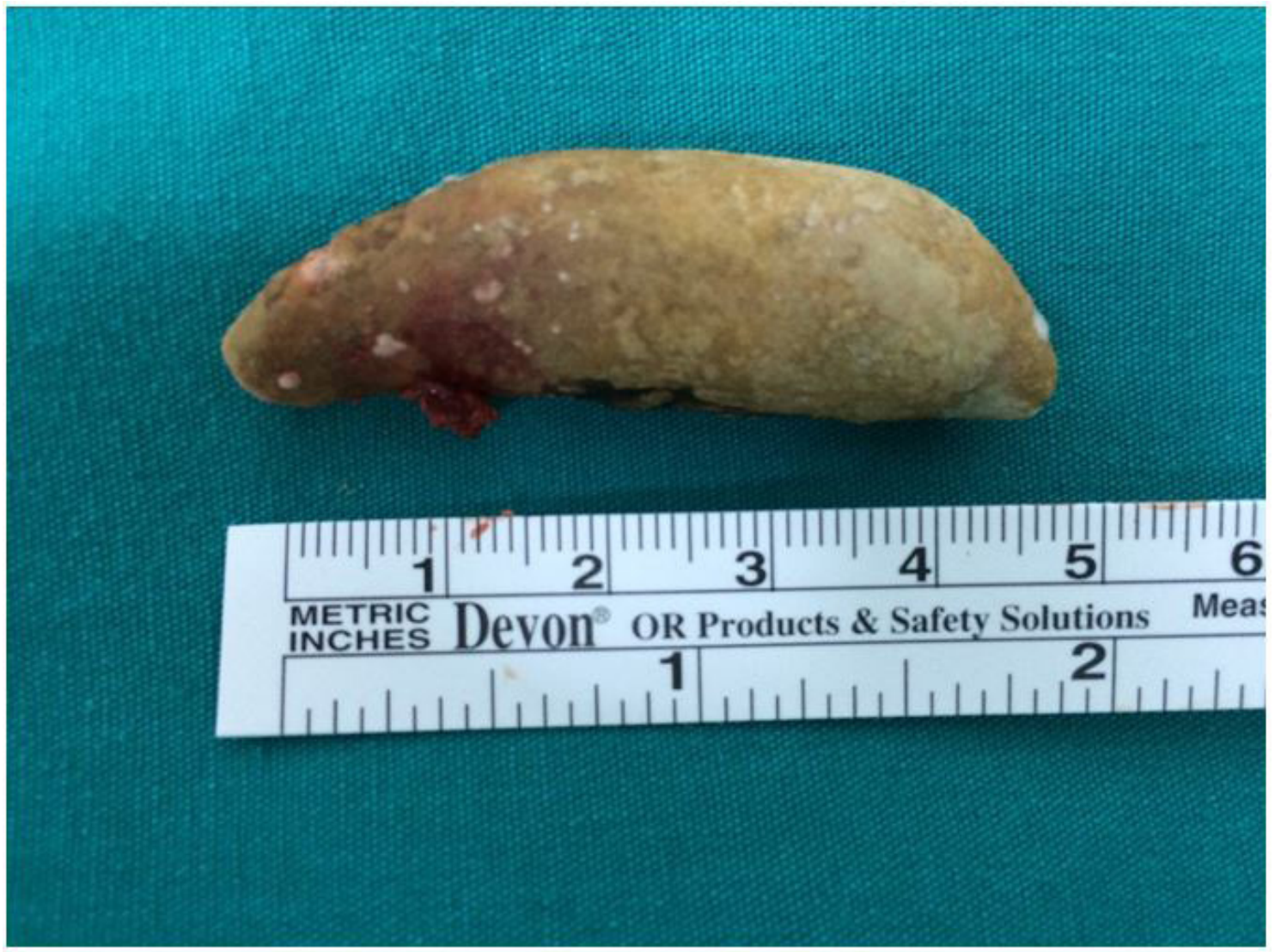

Figure 3: The giant ureteral stone after removal of the ureter 


\section{Discussion}

The prevalence of urolithiasis is low and being more common in developing than the industrialized countries [2]. Primary ureteral stones are very rare in children and usually secondary stones originated from kidney [1,3]. Ureteral stones are uncommon due to the smooth mucosa of ureter and regularly flowing of urine [3]. They may cause many symptoms or may be symptomless [4]. In primary cases there are some underlying pathologies like ureteroceles, ureteral duplication, ectopic ureter, tuberculosis, megaureter, polyp or neoplasms [1-3,5-10]. Furthermore stones may be occur because of the stasis due to ureterovesical junction stenosis or vesicoureteral reflux. We were not able to detect any evidence or underlying anatomic predisposition that could favor stone formation in our case. Our patient had metabolic hyperoxaluria.

Ureteral stones are growing longitudinally and for a long time; thence they do not cause acute obstruction such as our patient. His stone was originated probably from the kidney and stayed in the ureter for a long time; than caused stasis. Stasis prompted pyelonephritis and small kidney opposite to the left one.

The American Urological Association (AUA) guidelines, indicated that up to $98 \%$ of ureteral stones 4 mm or smaller will pass spontaneously which are based on a meta-analysis of the literature for adults [9,11]. However for childhood there is any clasification of sizes of the ureteral stones.

The etiology of urolithiasis in children is widely idiopathic; but some giant ureteral stones may occur with the effect of urinary pathologies or metobolic disorders [2,4]. Some predisposition metabolic disorders accompany to the urteral stones such as hypercalciuria, hypocitraturia, hyperoxaluria, hyperuricosuria and hypocitraturia. Rates of metabolic disorders are as high as $90 \%$ with the most common abnomalities being hypercalciuria and hypocitraturia [2]. Elmaci et al evaluated that primer ureteral stones were accompanied with hyperoxaluria and hypocitraturia in Turkey in 2014 [12]. Our patient had hyperuricosuria, hyperoxaluria and hypocitraturia entirely.

Calcium-oxalateephosphate stones accounting for $80 \%$ of all stones are the most stones in children; however struvite, uric acid and cystine stones are seen less frequently [7]. Our patients' stone analysis was composed of struvite. Struvite stones are often seen in younger age and male gender [13]. Clinical presentation of these stones are usually with urinary infection, renal colic and fever, gross hematuria [13]. Our patient had hematuria and renal colic. In the treatment of struvite stones in children, the underlying pathology must first be corrected. Since the stone of our patient was struvite stone, nutrition and hydration were regulated because it was mostly associated with infection. In addition, it was followed up with protective dual antibiotic therapy.

Actually the therapy of urteral stones depends on the size of the stone, morphology and the function of the affected kidney [8,14]. Extracorporeal shockwave lithotripsy (ESWL) and ureteroscopy are the most used noninvasive modalities of treatment [11]. However, these noninvasivbe techniques are not effective or usable for large size ureteral stones. Generally open surgery is using for large size ureteral stones $[1,4]$. We performed urterolitotomy and remove the stone in a short time without any complication. We have used Mc Burney incision but Wieslaw et al used Phannenstiel or an oblique Gibson incision leads to a wide dissection in the retroperitoneal space [15].

\section{Conclusion}

In conclusion the rarity and atipic clinic presentation of giant ureteral stones leads to slient progression and causes problems in differential diagnosis in childhood. Also we assumed that open surgery is more favourable treatment choice for giant pediatric ureteral stones.

\section{Conflict of interest}

All authors have no conflict of interest. 


\section{References}

1. Ozkan B, Sancaklı O, Demirkesen O (2003) Giant ureter stone in a young male patient: a case report [Genç erkek hastada dev ureter tasi: olgu sunumu]. Cerrahpaşa Tip Dergisi 34: 204-6.

2. Rahman N, Hitchcock R (2010) Case report of paediatric oxalate urolithiasis and a review of enteric hyperoxaluria. J Pediatr Urol 6: 112-6.

3. Kılınç I, Gedik A, Akın D (2009) Giant ureter bowl: case report [Dev üreter tası: olgu sunumu]. Dicle Tip Dergisi 36: 47-49.

4. Demirtas A, Sahin N, Akinsal EC, Ekmekcioglu O, Tatlisen A (2013) Primary obstructive megaureter with giant ureteral stone: a case report. Hindawi Publishing Corporation Case Reports in Urology 198592: 3 pages.

5. Eroglu M, Unsal A, Cimentepe E, Bakirtas H (2003) Giant ureteral stone associated with partial ureteral duplication. International Urology and Nephrology 35: 485-7.

6. Metin A, Bulut O, Atahan O, Kayigil O (1993) Giant ureteral calculus due to tuberculosis. Int Urol and Nephrol 25: 543-5.

7. Ozukutan BH, Kucukaydin M, Gunduz Z, Kabaklioglu M, Okur H, et al. (2000) Urolithiasis in childhood. Pediatr Surg. Int 16: 60-3.

8. Pinter AB, Andits M, Szemledy F (1998) Giant ureteral stone in a 4-year-old boy. Pediatr Surg Int 13: 202-3.

9. Sarikaya S, Resorlu B, Ozyuvali E, Bozkurt OF, Oguz U, et al. (2013) A giant ureteral stone without underlying anatomic or metabolic abnormalities: a case report. Hindawi Publishing Corporation Case Reports in Medicine 236286: 3 pages.

10. Terai A, Terachi T, Yoshida S (1989) Prolapsed benign polyp of ureter associated with giant ureteral calculus. Acta Urologica Japonica 35: 871-3.

11. Wu CF, Shee JJ, Lin WY, Lin CL, Chen CS (2004) Comparison between extracorporeal shock wave lithotripsy and semirigid ureterorenoscope with holmium: yag laser lithotripsy for treating large proximal ureteral stones. J Urol 172: $1899-902$.

12. Elmacı AM, Ece A, Akın F (2014) Pediatric urolithiasis: metabolic risk factors and follow-up results in a Turkish region with endemic stone disease. Urolithiasis 42: 421-6.

13. Ranabothu S, Bernstein AP, Drzewiecki BA (2018) Diagnosis and management of non-calcium-containing stones in the pediatric population. International Urology and Nephrology 50: 1191-8.

14. Delakas D, Daskalopoulos G, Karyotis I, Metaxari M, Cranidis A (2002) Giant ureteral stone in association with primary megaureter presenting as an acute abdomen. Eur J Radiol 41: 170-2.

15. Urbanowicz W, Honkisz I, Sulisławski J, Dobrowolska-Glazar B (2014) The retroperitoneal, inguinal approach to distal part of the ureter. Cent European J Urol 67: 108-11. 


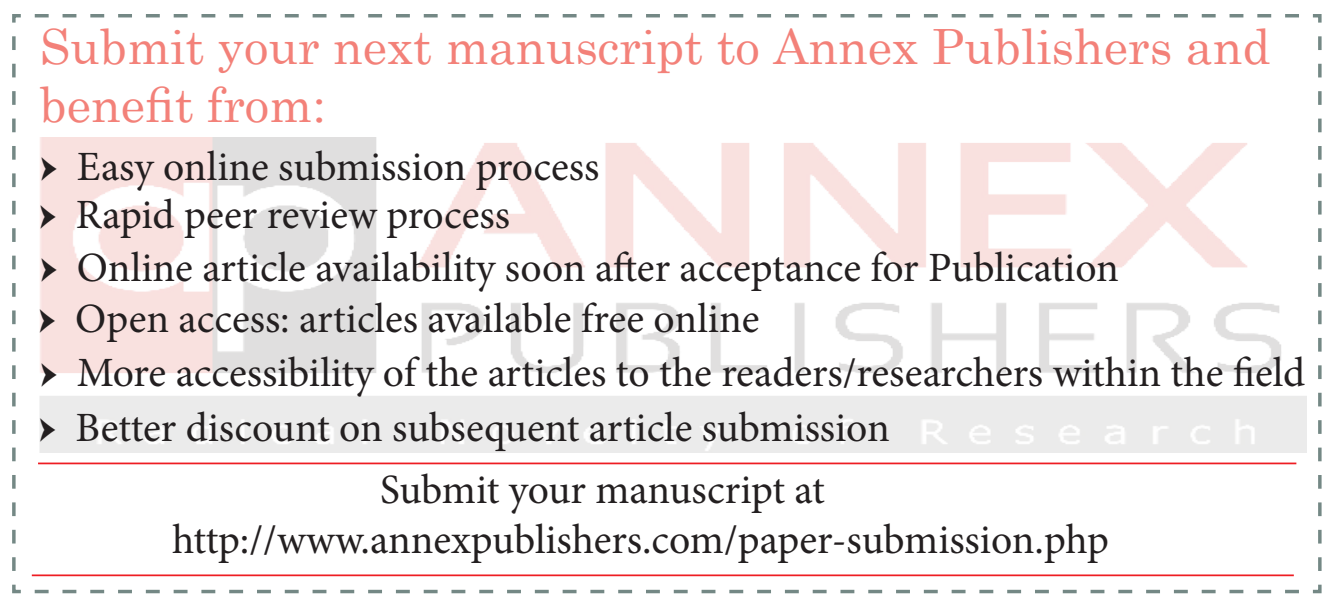

